Mónika Miklósi',2,3*

Tamás Martos ${ }^{4}$

Marianna Szabós

Krisztina Kocsis-Bogár ${ }^{1}$

Dóra Perczel Forintos

Semmelweis University,

Department of Clinical Psychology,

Budapest, 1083, Hungary

${ }^{2}$ Heim Pál Pediatric Hospital,

Centre of Mental Health,

Budapest, 1138, Hungary

${ }^{3}$ Eötvös Loránd University,

Psychological Institute,

Budapest, 1064, Hungary

${ }^{4}$ Semmelweis University,

Institute of Mental Health,

Budapest, 1089, Hungary

${ }^{5}$ The University of Sydney,

School of Psychology, Sydney,

2006, New South Wales, Australia

Received 05 February 2014 accepted 04 March 2014

\section{Introduction}

Stress defined in terms of perceptions of uncontrollability and unpredictability has been one of the central issues in behavioural medicine, partly because of its negative impact on physical and mental health [1]. Though recent studies have underlined the effects of stress on brain functioning, stress-related changes in cognitive processes of emotion regulation have been under-investigated [2].

Emotion regulation has been defined as the physiological, motivational, behavioural, and cognitive processes responsible for monitoring, evaluating, and modifying emotional reactions in order to accomplish one's goals [3], and has been considered to be important for understanding the onset, maintenance, and treatment of anxiety disorders (see [4] for review).

Cognitive regulation of emotion refers to conscious cognitive methods of emotion regulation including attentional and evaluative processes $[5,6]$. A possible way to characterize

\title{
COGNITIVE EMOTION REGULATION AND STRESS: A MULTIPLE MEDIATION APPROACH
}

\section{Abstract}

Background and purpose: Chronic stress leads to deficits in executive functions; its effect on cognitive emotion regulation has yet to be investigated. The present study explores the possible role of cognitive emotion regulation strategies in mediating the well-established association between perceived stress and anxiety. We assumed it should be that, via impaired prefrontal activity and executive functions, stress leads to the reduced use of executive strategies and the increased use of non-executive strategies, resulting in higher levels of anxiety. Methods: A cross-sectional sample of 162 university students completed the Perceived Stress Scale, the Spielberger Trait Anxiety Inventory, and the Cognitive Emotion Regulation Questionnaire. Results: Multiple mediation analysis resulted in a significant model, in which cognitive emotion regulation strategies mediated the effect of perceived stress on anxiety (Adjusted $R^{2}=0.68, F_{12.149}=29.30, p<0.001$, effect ratio $=0.22$ ). Specifically, greater stress was found to be uniquely related to increased use of non-executive strategies (self-blame, rumination, and catastrophizing) and decreased use of cognitive strategies involving executive functions (positive reappraisal and putting into perspective). Greater use of non-executive strategies and reduced use of executive strategies (except for putting into perspective) was in turn found to be associated with higher levels of anxiety. Conclusions: These results seem to suggest that under stressful conditions - precisely when control is most needed - cognitive regulation may be ineffective in controlling emotional responses. Implications for preventing the negative effects of stress are highlighted.

Keywords

- Cognitive emotion regulation • Executive functions $\cdot$ Perceived stress • Anxiety • Multiple mediation

(c) Versita Sp. z o.o

cognitive strategies of emotion regulation is in terms of the involvement of the executive functions $[7,8]$. Executive cognitive emotion regulation, e.g. reappraisal, implies the use of higher cognitive processes such as mental set-shifting, evaluation, planning, working memory, and information updating and monitoring, whereas non-executive cognitive strategies, such as rumination, are associated with deficits in executive functions, e.g. attentional inflexibility or inhibitory deficits [8]. For example, reappraisal was shown to be associated with enhanced affective flexibility [9], interference resolution [10], and working memory capacity [11], while rumination was associated with decreased cognitive flexibility [12] and internal shifting impairments in working memory [13].

Converging results have revealed that negative emotional states are strongly related to the excessive use of non-executive cognitive emotion regulation strategies, particularly rumination, catastrophizing, and self-blame.
Low use of executive strategies, such as positive reappraisal, has also been found to be connected to psychopathology [e.g. 14-17], as well as to negative emotional states such as irritability and anger [18].

Executive functions depend on the structural and functional integrity of the prefrontal cortex (PFC) [19], which guides emotions and behaviour through projections to subcortical regions like the hypothalamus and the amygdala [20]. Under safe conditions, the amygdala, which has been suggested to serve as a rapid detector of potential threats, is under tonic inhibitory control by the PFC. Under stressful conditions, critical areas of the PFC become hypoactive, resulting in a hyperactivation of the amygdala, which leads to the evocation of adaptive fear responses, but might also lead to chronic threat perception and sustained fear in unpredictable conditions (see [21] for review).

Recent research in animal models demonstrates that exposure to stress is

*E-mail:miklosi.monika@ppk.elte.hu 
sufficient to cause deficits in executive functions such as working memory, attentional set-shifting and cognitive flexibility; these deficits are associated with the impairment of the PFC (see [22] for review). In humans, stress induction resulted in a significant decrease in reward-related responses in the medial PFC [23]. Furthermore, stress in terms of perceived uncontrollability was associated with blunted neural responses in the medial PFC [24]. In line with these findings, exposure to high or very high levels of stress was shown to impair hippocampus- and prefrontal cortex-related functions such as explicit memory and flexible reasoning (see [25] for review).

It is therefore reasonable to assume that stress would lead - via impaired PFC and executive functioning - to a reduced use of executive and an increased use of non-executive cognitive emotion regulation strategies.

We found only one study exploring the direct effect of stress on the cognitive control of emotion. Raio et al. [2] found that an experimentally stressed group was less able to apply a previously acquired cognitive regulatory strategy including reappraisal than an unstressed control group. In discussing their findings, these authors concluded that under stressful conditions - precisely when control is most needed - cognitive regulation may be ineffective at controlling emotional responses.

In another study, Geisler et al. [8] found that an increase in executive cognitive emotion regulation mediated the positive effect of higher resting heart rate variability (HRV) on subjective well-being. HRV was previously shown to be associated with executive functioning $[26,27]$ and the activity of the PFC [28], and has also been suggested to be a biomarker for stress [21], so these results provide indirect support for the hypothesis of Raio et al. [2].

The aim of our study was to investigate the hypothesized role of a broader range of executive and non-executive emotion regulation strategies in mediating the wellestablished association between psychological stress and anxiety. According to the hypothesis of Raio et al. [2], the use of specific cognitive strategies would depend on perceptions of stress. Specifically, higher perceived levels of stress may be associated with the use of more non-executive cognitive strategies (for example self-blame, rumination, and catastrophizing) and fewer executive strategies (for example positive reappraisal or positive refocusing). The use of non-executive strategies is predicted to be related to increased stress-related anxiety, while the use of executive strategies is predicted to mediate lower levels of anxiety.

\section{Experimental Procedures}

\section{Participants}

A cross-sectional convenience sample of 162 Hungarian undergraduate and postgraduate university students, 102 males (63.6\%) and 60 females (36.4\%) completed a questionnaire packet. The mean age of participants was 25.78 years $(S D=9.43$, range: $18-55)$. Men and women did not differ in age $(M=26.08, S D=$ 9.14 and $M=25.27, S D=9.96$, respectively; $t(160)=0.53, p=0.60)$.

\section{Measures}

Cognitive Emotion Regulation Questionnaire (CERQ) [14]. To assess cognitive strategies of emotion regulation, we used the CERQ which is a multidimensional self-report measure consisting of 36 Likert-type items (from 1, almost never to 5, almost always), with nine subscales targeting intercorrelated but conceptually different cognitive coping strategies. Higher scores represent greater use of the specific strategy. For categorization of the cognitive strategies into executive and non-executive groups, we followed the results of Geisler et al. [8]. According to their factoranalytic study, self-blame (the appraisal of the individual's responsibility for what one has experienced), rumination (keeping the focus of attention on the negative feelings and thoughts associated with the events), and catastrophizing (an overestimation the most negative aspects of the situation) were considered to be non-executive strategies, and refocus on planning (focusing on what to do to change the situation), positive reappraisal (giving a positive meaning to the event), putting into perspective (extending the focus of attention and lessening the impact of the negative event by comparing it with other events), and positive refocusing (the deployment of attention away from the negative event) were considered to be executive strategies. Two remaining subscales were not categorized by Geisler et al. [8], so we included blaming others (the appraisal that others bear the responsibility for what has happened) and acceptance (accepting the experience as it happened) to our analysis in an exploratory way. CERQ has been validated in adolescent and adult samples (29). Cronbach's alphas of the scales ranged from 0.68 to 0.93 . The Hungarian version of the CERQ showed acceptable to very good internal consistency (as ranging from 0.68 to 0.88 ) and strong test-retest reliability ( $r$ s ranging from 0.58 to 0.88 ) for the separate subscales. Furthermore, confirmatory factor analysis supported the theoretical nine-factor model $\left(x^{2}=1042.72 d f\right.$ $=561, p<0.001 ; X^{2}=1.86 ; \mathrm{CFI}=0.88 ;$ SRMR $=$ 0.09; RMSEA $=0.06,90 \% \mathrm{Cl}: 0.05-0.06$ ) [30]. In this study, alpha scores were acceptable for acceptance ( $a=0.67$ ) and ranged from 0.70 to 0.88 for the other subscales, which indicates good to very good internal consistencies.

Perceived Stress Scale, 4-item version (PSS4) [31]. The PSS measures the degree to which life situations were appraised as stressful in terms of general unpredictability and uncontrollability in the course of the previous month ("In the last month, how often have you felt difficulties were piling up so high that you could not overcome them?"). The original scale [31] consists of 14 items with Likert-type response format (from 1, never to 5, very often). The four-item version (PSS4) [32] was shown to be a useful measure of perceived stress for situations requiring a brief scale. Validity and reliability of the Hungarian version has been reported by Stauder and Konkolÿ-Thege [33]. The PSS4 was strongly correlated to the original scale $(r=0.93)$, showed good internal consistency ( $a=0.79$ ) and excellent stability (test-retest $r=0.90)$. In this study, internal consistency of the 4-item version of the Perceived Stress Scale was very good $(a=0.83)$.

Trait subscale of the State-Trait Anxiety Inventory (STAI-T) [34]. STAI is the most widely used self-report measure of anxiety and has been validated across gender and ethnic groups [35]. While state anxiety refers the emotional responses when confronted 
with specific threatening events and can, no doubt be viewed as a measure of "fear", trait anxiety can be defined as feelings of tension, apprehension, worry, and discomfort experienced across various situations, and so can be viewed as a marker of sustained fear. We assessed STAI-T consisting of 20 items describing how people generally feel with a Likert-type response format (from 1 almost never to 4 almost always). The authors reported excellent internal consistency ( $a=0.92)$. The validity and reliability of the Hungarian version has been reported by Sipos and Sipos [36]. The subscales showed very good to excellent internal consistencies (0.85 and 0.90) and strong test-retest correlations ( 0.86 and 0.73 ). In this study, the trait-anxiety subscale of STAI showed excellent internal consistency ( $\alpha=$ 0.90).

\section{Procedure}

The work described here has been carried out in accordance with The Code of Ethics of the World Medical Association (Declaration of Helsinki) for experiments involving humans. Ethical approval was obtained from the Institutional Ethical Committee of Semmelweis University, Budapest, Hungary. Students were asked to stay behind after lectures to fill in the questionnaires and were tested in groups after informing them about anonymity and confidentiality as well as receiving their written consent. No compensation was given for participation

\section{Statistical analyses}

Data were analyzed using IBM SPSS Statistics 20 [37]. An a-level of 0.05 was considered to be significant, using Bonferroni correction for multiple statistical tests. Gender differences were tested by means of independentsamples t-tests. Bivariate relationships of the study variables were tested using Pearson's correlation coefficients. To test the possible mediational effects of cognitive emotion regulation strategies on the relationship between perceived stress and anxiety, total, direct, and indirect effects (total and specific for each mediator) were calculated using the multiple mediation approach and SPSS macro provided by Preacher and Hayes [38]. Boxcox and logarithmic transformations were used to assure normality. Bootstrapping with a resample procedure of 1,000 bootstrap samples (bias corrected and accelerated (BCa) estimates and $95 \%(C l)$ was used for significance testing, because this method does not impose the assumption of normality of the sampling distribution [38]. Effect ratios were calculated to express the amount of the total effect that is explained by the (total) indirect effects via the mediators. Because of the previously reported differences in the use of cognitive emotion regulation strategies across demographical groups [39-42], age and gender were included as covariates.

\section{Results}

Descriptive statistics and reliabilities of the measures used in the study are shown in Table 1, along with the zero-order Pearson correlation coefficients among the variables. Age was not significantly associated with PSS4, STAI-T and CERQ subscales (Table 1). Women scored significantly higher on both PSS4 $\left(M_{\text {women }}\right.$ $=8.40, S D_{\text {women }}=3.17, M_{\text {men }}=7.19, S D_{\text {men }}=2.72$, $t(160)=2.57, p=0.01)$ and STAI-T $\left(M_{\text {women }}=\right.$ $25.15, S D_{\text {women }}=9.42, M_{\text {men }}=21.86, S D_{\text {men }}=8.09$, $t(160)=2.35, p=0.02)$. Men and women did not differ with regard to CERQ subscales $(p>0.05)$.

Results of the multiple mediations are presented in Table 2 and Figure 1. First, we calculated total, direct, and total indirect effects

Table 1. Descriptive statistics, reliabilities and correlations of study variables.

\begin{tabular}{|c|c|c|c|c|c|c|c|c|c|c|c|c|c|}
\hline & Mean (SD) & $a$ & 2. & 3. & 4. & 5. & 6. & 7. & 8. & 9. & 10. & 11. & 12. \\
\hline 1. CERQ Self-blame & $11.11(2.70)$ & 0.74 & $0.37^{*}$ & $0.34^{*}$ & 0.04 & 0.01 & -0.12 & 0.18 & 0.14 & -0.21 & $0.34^{*}$ & $0.40^{*}$ & -0.20 \\
\hline 2. CERQ Rumination & $12.15(3.70)$ & 0.83 & 一 & $0.42^{*}$ & $0.25^{*}$ & 0.00 & 0.03 & 0.01 & $0.32^{*}$ & -0.13 & $0.33^{*}$ & $0.41^{*}$ & -0.23 \\
\hline 3. CERQ Catastrophizing & $7.30(2.72)$ & 0.70 & - & - & $0.26^{*}$ & -0.18 & -0.16 & 0.04 & 0.06 & -0.14 & $0.37^{*}$ & $0.43^{*}$ & 0.02 \\
\hline 4. CERQ Other-blame & $8.49(2.42)$ & 0.76 & - & - & - & 0.03 & 0.02 & 0.07 & 0.06 & 0.06 & 0.11 & 0.22 & -0.06 \\
\hline 5. CERQ Refocus on planning & $15.75(2.67)$ & 0.80 & - & - & - & - & $0.35^{*}$ & 0.19 & 0.00 & $0.29 *$ & $-0.37^{*}$ & $-0.31^{*}$ & -0.01 \\
\hline 6. CERQ Positive reappraisal & $14.14(3.18)$ & 0.79 & - & - & - & - & - & $0.51^{*}$ & $0.27^{*}$ & $0.29^{*}$ & $-0.26^{*}$ & $-0.37^{*}$ & -0.03 \\
\hline 7. CERQ Putting into perspective & $11.89(3.47)$ & 0.76 & - & - & - & - & - & - & 0.15 & $0.33^{*}$ & -0.16 & -0.08 & 0.15 \\
\hline 8. CERQ Acceptance & $11.42(2.85)$ & 0.67 & - & - & - & - & - & - & - & 0.03 & 0.10 & 0.07 & -0.16 \\
\hline 9. CERQ Positive refocusing & $11.00(3.72)$ & 0.88 & - & - & - & - & - & - & - & - & -0.22 & $-0.28^{*}$ & 0.13 \\
\hline 10. PSS4 & $7.64(2.95)$ & 0.83 & - & - & - & - & - & - & - & - & - & $0.75^{*}$ & -0.14 \\
\hline 11. STAI-T & $23.08(8.72)$ & 0.90 & - & - & - & - & - & - & - & - & - & - & -0.08 \\
\hline 12. Age & $25.78(9.43)$ & - & - & - & - & - & - & - & - & - & 一 & - & - \\
\hline
\end{tabular}

$\mathrm{N}=162$; SD - Standard deviation, CERQ - Cognitive Emotion Regulation Questionnaire, PSS4 - Perceived Stress Scale, 4 item version, STAI-T - Spielberger State-Trait Anxiety Inventory, Trait subscale; ${ }^{*} p<0.004$ (0.05/12 using Bonferroni correction). 
to test the hypothesis that, together, the set of cognitive strategies mediate the effect of perceived stress on anxiety. The total and direct effects of perceived stress on anxiety were 0.67 , $(p<0.001)$ and $0.52(p<0.001)$, respectively. The total indirect effect through the nine mediators was 0.15 (95\% BCa bootstrap Cl: 0.08 -0.23 , effect ratio $=0.22$ ).

To test our hypothesis regarding individual mediators in the context of a multiple mediator model, we investigated the specific indirect effects for each presumed mediator (defined as the product of the two unstandardized paths linking perceived stress to anxiety via that mediator). An examination of the specific indirect effects indicates that positive reappraisal was clearly the strongest mediator, explaining about $44.3 \%$ of the total indirect (mediated) effect. Self-blame, rumination, and putting into perspective were also significant mediators according to the bootstrap method, controlling for all other mediators and covariates in the model (Table 2).

Paths $A$ and $B$ in Figure 1 indicate that greater perceived stress was related to a greater use of self-blame and rumination, and a lesser use of positive reappraisal, which in turn were associated with higher levels of anxiety. In the case of the fourth significant mediation effect, findings revealed that a higher level of perceived stress was related to a lower use of putting into perspective. Lower levels of putting into perspective were in turn associated with higher levels of anxiety.

Greater perceived stress was also related to a greater use of catastrophizing and a lesser use of refocus on planning and positive refocusing. These cognitive emotion regulation strategies did not, however, mediate the relationship between perceived stress and anxiety.

\section{Discussion and conclusion}

Results from various lines of research revealed that stress strongly impacts brain functioning by promoting a shift from flexible, "cognitive" to rather rigid "habit" systems, which might be generally adaptive in response to a physical threat, by leading to rapid threat evaluation and the activation of the "fight or flight" response, a strong stress-related

Table 2. Mediation of the effect of perceived stress on anxiety through cognitive emotion regulation strategies.

\begin{tabular}{|c|c|c|c|c|c|}
\hline & B & SE & $t$ & $p$ & $\mathrm{BCa} 95 \% \mathrm{Cl}$ \\
\hline Total effect & 0.67 & 0.05 & 14.66 & $<0.001$ & \\
\hline Direct effect & 0.52 & 0.05 & 10.55 & $<0.001$ & \\
\hline \multicolumn{6}{|l|}{ Partial effect of control variables } \\
\hline Gender & 0.04 & 0.25 & 0.14 & 0.89 & \\
\hline Age & 0.01 & 0.01 & 0.92 & 0.36 & \\
\hline Total indirect effect & 0.15 & 0.04 & & & $0.08-0.23$ \\
\hline \multicolumn{6}{|l|}{ Specific indirect effects } \\
\hline CERQ Self-blame & 0.04 & 0.02 & & & $0.01-0.08$ \\
\hline CERQ Rumination & 0.03 & 0.02 & & & $0.01-0.07$ \\
\hline CERQ Catastrophizing & 0.02 & 0.02 & & & $-0.01-0.06$ \\
\hline CERQ Other-blame & 0.01 & 0.01 & & & $0.00-0.04$ \\
\hline CERQ Refocus on planning & 0.00 & 0.02 & & & $-0.03-0.03$ \\
\hline CERQ Positive reappraisal & 0.07 & 0.03 & & & $0.03-0.13$ \\
\hline CERQ Putting into perspective & -0.03 & 0.02 & & & $-0.07--0.01$ \\
\hline CERQ Acceptance & 0.00 & 0.01 & & & $-0.01-0.02$ \\
\hline CERQ Positive refocusing & 0.01 & 0.01 & & & $0.00-0.05$ \\
\hline Model summary & \multicolumn{5}{|c|}{$\begin{array}{c}\mathrm{R}^{2}=0.70, \text { adjusted } \mathrm{R}^{2}=0.68 \\
\mathrm{~F}_{12,149}=29.30, \mathrm{p}<0.001\end{array}$} \\
\hline Effect ratio & \multicolumn{5}{|c|}{0.22} \\
\hline
\end{tabular}

$N=162$; Outcome variable is trait-anxiety. The specific indirect effects listed in the table are the products of Path $A$ and Path B coefficients in Figure 1. CERQ - Cognitive Emotion Regulation Questionnaire, SE - standard error of the indirect effect, BCa 95\% Cl- Bias-corrected and accelerated 95\% confidence interval; Number of bootstrap resample: 1000.

memory formation relevant to the learning context [43], and an avoidance of hesitation and delay. The costs are decreased flexibility and outcome evaluation, a lack of explicit knowledge, and poorly integrated memory contents. These ancient strategies of response to physical threats might be inappropriate when confronting psychological threats and the challenges of modern life, and might lead to psychopathology $[1,43]$. For example, the shift from declarative to procedural memory systems under trauma has been considered to be responsible for intrusions and the perception of a present threat in post-traumatic stress disorder [44]. In panic disorder, enhanced contextual learning and reduced awareness of outcomes (i.e. the failure of integrating the experience, that the predicted negative outcome has not occurred) might also be due to stress-dependent shift between memory systems [43].

The question arises whether stress-induced changes in the cognitive regulation of emotions also exhibit this shift from flexible strategies involving executive functions and the activation of the prefrontal cortex to more inflexible processes, and what we can say about the role this shift plays in the success or failure of adaptation.

To our knowledge, this study is the first to investigate the role of various cognitive emotion regulation strategies in the wellestablished relationship between perceived stress and negative emotion using the multiple mediator approach. 


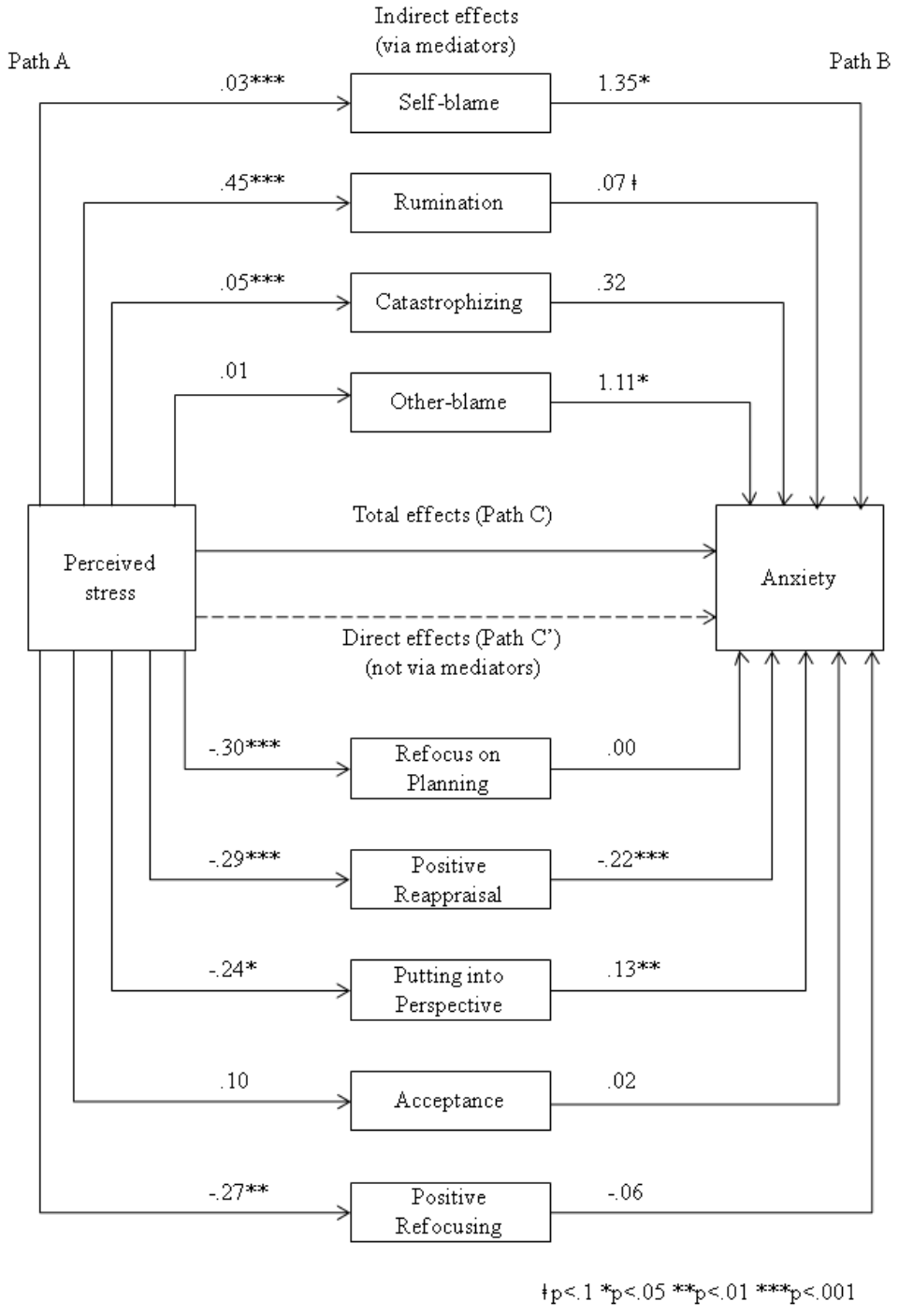

Figure 1. Indirect effects of perceived stress on anxiety, as mediated by individual cognitive coping strategies (unstandardized regression coefficients) Note. Age and gender are included in the model as covariates but not represented in the figure for reasons of clarity.

Based on the literature in this filed [e.g. 33] we expected a strong positive correlation between perceived stress and anxiety and our results support this hypothesis. Bivariate analyses revealed that, consistent with previous findings [e.g. 29], non-executive cognitive strategies (self-blame, rumination, and catastrophizing) were intercorrelated, and showed significant positive correlations of medium effect size with both perceived stress and anxiety. On the other hand, as expected, significant negative associations of small to medium effect sizes were found between executive strategies (refocus on planning, positive reappraisal, and positive refocusing) and both perceived stress and anxiety.

Contrary to other studies [e.g. 36,40,41,45], age was not significantly related to perceived stress, anxiety, and cognitive emotion regulation. This might be due to the fact that our sample consisted of university students from a relatively restricted age range.

In line with the literature [e.g. 36,45], we found significant gender differences in perceived stress, as well as anxiety. While in previous research males and females significantly differed in the use of rumination, putting into perspective, and blaming others [42], we were not able to replicate these findings. This was probably due to lower statistical power in relation to sample size.

Results of the multiple mediation analysis indicated that cognitive emotion regulation strategies, both in combination and individually, mediate the effect of perceived stress on anxiety. About $22 \%$ of the total effect of perceived stress on anxiety was explained by the nine mediators taken together. However, the significance of both the direct and the indirect effects suggests partial mediation. In the multivariate analysis, age and gender were not significant predictors of anxiety.

When examining the role of specific cognitive emotion regulation strategies, our results indicate that, in line with our hypothesis, greater perceived uncontrollable stress was related to the increased use of nonexecutive strategies (self-blame, rumination, and catastrophizing) and decreased use of cognitive strategies (positive refocusing, positive reappraisal, refocus on planning, and putting into perspective) that are considered to involve executive functioning. These results are in line with previous research on the effect of stress on cognitive emotion regulation $[2,8]$ and extend previous findings by a more detailed analysis of the role of specific cognitive strategies.

When looking at the directions of the significant mediational effects, we can conclude that greater perceived stress is associated with higher levels of anxiety via the higher use of some non-executive cognitive strategies (self-blame and rumination) and the lower use of positive reappraisal involving executive functions. These results add to the growing literature regarding the importance of these cognitive strategies in the development of psychopathology [e.g. 14-17] and point to the malign effect of uncontrollability and unpredictability appraisals in facilitating the use of non-executive emotion regulation strategies while inhibiting the use of executive strategies at the same time.

The fourth significant mediational effect (putting into perspective) shows a somewhat 
more complicated picture. Results revealed that, as expected, higher levels of perceived stress are related to the decreased use of this cognitive strategy. However, our findings did not support previous suggestions that putting into perspective may be an adaptive strategy resulting in a reduction of negative emotions [14]. Instead, the increased use of putting into perspective was associated with increased anxiety in the present study. These findings are consistent with previous studies reporting positive associations between the use of putting into perspective and psychopathology $[15,46]$. When discussing their findings, Schroevers, et al. [46] argued that putting into perspective might be associated with other strategies (e.g. positive refocusing and positive reappraisal) and might be less adaptive than these strategies. At the same time it might be positively related to psychopathology when controlling for the effect of these more adaptive strategies. This is in fact what our results have shown. More research is needed to gain a clear understanding about the effect of putting into perspective on negative emotion.

Our negative findings regarding the relationships between stress as well as anxiety and the two remaining cognitive strategies involved in the CERQ (acceptance and blaming others) are in line with the results of Geisler et al. [8], suggesting that these strategies cannot be characterized as executive or non-executive strategies.

A major limitation of this study was its crosssectional setting, which did not permit causal conclusions. It seems plausible to assume that the relationship between stress-perception and negative emotion is bidirectional; increased perceived stress leads (partially through changes in cognitive emotion regulation) to higher levels of anxiety, which in turn causes differences in stress-perception. Self-report measures might also be biased by contextual factors, memory and socially desirable responses. Considering the fact that the maturation of underlying neural structures continues into young adulthood [47], our results in a sample of university students might not be generalizable for other age-groups.

Further studies are required to replicate our findings in longitudinal designs, complementing the present data by using multimethod assessments, e.g. both self-report and physiological measures of emotional states. Our study focused on cognitive strategies people use in general when facing stressful events; further studies should extend our research by exploring the effects of perceived stress and various cognitive strategies on emotional responses for different negative life-events, using situational measures of anxiety.

Despite these limitations, our findings underline the importance of cognitive emotion regulation strategies in the relationship between psychological stress and anxiety, and have clear clinical implications. Our results suggest that, with increasing perceived stress, people give up executive cognitive strategies, such as changing the focus of attention to more pleasant things or searching for positive meaning in the situation, and engage in non-executive strategies, e.g. chains of unproductive negative thoughts or blaming themselves for what has happened. Changes in the use of cognitive strategies might then lead to escalation of negative emotions, which can, in turn, exacerbate the use of non-executive strategies. We can conclude that the regulation of emotions under stress also shows the picture which has been described regarding other cognitive functions, characterized by a shift from cognitive, executive regulation to more inflexible, non-executive regulation. This pattern of emotion regulation seems to be non-adaptive, however. The rapid changes of modern life might seem not to leave enough time to evolve appropriate regulatory processes under circumstances of psychological stress and this includes the management of negative emotions, which contributes to the development of psychopathology including anxiety and mood disorders.

The effect of chronic stress on executive functions and on the underlying neural activity has been shown to be reversible [48]. In line with this, previous research revealed that psychotherapy can lead to alterations in fronto-limbic activity in anxiety disorders [e.g. 49]; however, there is a lack of knowledge regarding the mechanisms of this effect. Our results suggest that specific therapeutic interventions targeting cognitive emotion regulation strategies by helping people maintain the use of executive strategies and avoid non-executive strategies under stress might be crucial in the prevention of negative consequences of psychological stress. Such interventions resulting in the predominance of executive strategies might lead to the increased activation of the PFC, set top-down regulatory processes afloat [6], and might decrease the individual's vulnerability to stress.

\section{Acknowledgment}

None of the authors have any conflicts of interest to declare.

References

[1] Kopp M., Réthelyi J., Where psychology meets physiology: chronic stress and premature mortality - the Central-Eastern European health paradox, Brain Res. Bull., 2004, 62, 351-367

[2] Raio C.M., Orederu T.A., Palazzolo L., Shurick A.A., Phelps E.A., Cognitive emotion regulation fails the stress test, Proc. Natl. Acad. Sci. USA, 2013, 110, 15139-15144

[3] Thompson R.A., Emotion regulation: a theme in search of definition, Monogr. Soc. Res. Child. Dev., 1994, 59, 25-52
[4] Cisler J.M., Olatunji B.O., Emotion regulation and anxiety disorders, Curr. Psychiatry Rep., 2012, 14, 182-187

[5] Garnefski N., Kraaij V., Spinhoven P., Negative life events, cognitive emotion regulation and emotional problems, Pers. Individ. Dif., 2001, 30, 1311-1327

[6] Ochsner K.N., Gross J.J., Cognitive emotion regulation: Insights from social cognitive and affective neuroscience, Curr. Dir. Psychol. Sci., $2008,17,153-158$ 
[7] Zelazo P.D., Cunningham W.A., Executive function: Mechanisms underlying emotion regulation, In: Gross J.J. (Ed.), Handbook of emotion regulation, Guilford Press, New York, 2007

[8] Geisler F.C.M., Vennewald N., Kubiak T., Weber H., The impact of heart rate variability on subjective well-being is mediated by emotion regulation, Pers. Individ. Dif., 2010, 49, 723-728

[9] Malooly A.M., Genet J.J., Siemer M., Individual differences in reappraisal effectiveness: the role of affective flexibility, Emotion, 2013, 13, 302-313

[10]Pe M.L., Raes F., Koval P., Brans K., Verduyn P., Kuppens P., Interference resolution moderates the impact of rumination and reappraisal on affective experiences in daily life, Cogn. Emot., 2013, 27, 492-501

[11] McRae K., Jacobs S.E., Ray R.D., John O.P., Gross J.J., Individual differences in reappraisal ability: links to reappraisal frequency, wellbeing, and cognitive control, J. Res. Pers., 2012, 46, 2-7

[12] Davis R.N., Nolen-Hoeksema S., Cognitive inflexibility among ruminators and nonruminators, Cogn. Ther. Res., 2000, 24, 699-711

[13] De Lissnyder E., Koster E.H.W., De Raedt R., Emotional interference in working memory is related to rumination, Cogn. Ther. Res., 2012, 36, 348-357

[14] Garnefski N., Kraaij V., Spinhoven P., Negative life events, cognitive emotion regulation and emotional problems, Pers. Individ. Dif., 2001, 30, 1311-1327

[15] Garnefski N., Boon S., Kraaij V., Relationships between cognitive strategies of adolescents and depressive symptomatology across different types of life event, J. Youth Adolesc., 2003, 32, 401-408

[16] Garnefski N., Kraaij V., Relationships between cognitive emotion regulation strategies and depressive symptoms: a comparative study of five specific samples, Pers. Individ. Dif., 2006, 40, 1659-1669

[17] Jermann F., Van Der Linden M., D'Acremont M., Zermatten A., Cognitive Emotion Regulation Questionnaire (CERQ): Confirmatory factor analysis and psychometric properties of the French translation, Eur. J. Psychol. Assess., 2006, 22, 126-131

[18] Martin R.C., Dahlen E.R., Cognitive emotion regulation in the prediction of depression, anxiety, stress, and anger, Pers. Individ. Dif., 2005, 39, 1249-1260

[19] Goldman-Rakic P.S., The pre-frontal landscape: implications of functional architecture for understanding human mentation and the central executive, Philos. Trans. R. Soc. Lond. B Biol. Sci., 1996, 351, 1445-1453

[20] Shansky R.M., Lipps J., Stress-induced cognitive dysfunction: hormone-neurotransmitter interactions in the prefrontal cortex, Front. Hum. Neurosci., 2013, 7, 123

[21] Thayer J.F., Åhs F., Fredrikson M., Sollers J.J., Wager T.D., A metaanalysis of heart rate variability and neuroimaging studies: Implications for heart rate variability as a marker of stress and health, Neurosci. Biobehav. Rev., 2012, 36, 747-756

[22] Holmes A., Wellman C.L., Stress-induced prefronal reorganization and executive dysfunction in rodents, Neurosci. Biobehav. Rev., 2009, $33,773-783$
[23] Ossewaarde L., Qin S., Van Marle H.J.F., van Wingen G.A., Fernández G., Hermans E.J., Stress-induced reduction in reward-related prefrontal cortex function, Neuroimage, 2011, 55, 345-352

[24] Treadway M.T., Buckholtz J.W., Zald D.H., Perceived stress predicts altered reward and loss feedback processing in medial prefrontal cortex, Front. Hum. Neurosci., 2013, 7, 180

[25] Sandi C., Stress and cognition, WIREs Cogn. Sci., 2013, 4, 245-261

[26] Hovland A., Pallesen S., Hammar T., Hansen A.L., Thayer J.F., Sivertsen B., et al., The relationships among heart rate variability, executive functions, and clinical variables in patients with panic disorder, Int. J. Psychophysiol., 2012, 86, 269-275

[27] Mathewson K.J., Jetha M.K., Drmic I.E., Bryson S.E., Goldberg J.O., Hall G.B., et al., Autonomic predictors of stroop performance in young and middle-aged adults, Int. J. Psychophysiol., 2010, 76, 123-129

[28] Duschek S., Wörsching J., Reyes Del Paso G.A., Interactions between autonomic cardiovascular regulation and cortical activity: a CNV study, Psychophysiology, 2013, 50, 388-397

[29] Garnefski N., Kraaij V., Spinhoven P., Manual for the Use of the Cognitive Emotion Regulation Questionnaire, DATEC, Leiderdorp, The Netherlands, 2002

[30] Miklósi M., Martos T., Kocsis-Bogár K., Perczel Forintos D., [Psychometric properties of the Hungarian version of the Cognitive Emotion Regulation Questionnaire]. A kognitiv Érzelem-Regulació Kérdőiv magyar változatának pszichometrial jellemzői, Psychiatr. Hung., 2011, 26, 102-111

[31] Cohen S., Perceived stress in a probability sample of the United States The social psychology of health, Sage Publications Inc., Thousand Oaks, CA, USA, 1988

[32] Cohen S., Kamarck T., Mermelstein R., A global measure of perceived stress, J. Health Soc. Behav., 1983, 24, 385-396

[33] Stauder A., KonkolÿThege B., [Characteristics of the Hungarian version of the Perceived Stress Scale (PSS)], Az Észlelt Stressz Kérdőív (PSS) magyar verziójának jellemzői, Mentalhigiéné és Pszichoszomatika, 2006, 7, 203-216

[34] Spielberger C.D., Gorsuch R.L., Lushene R.E., Manual for the StateTrait Anxiety Inventory, Consulting Psychologist Press, Palo Alto, CA, USA, 1970

[35] Novy D.M., Nelson D.V., Goodwin J., Rowzee R.D., Psychometric comparability of the State-Trait Anxiety Inventory for different ethnic subpopulations, Psychol. Assess., 1993, 5, 343-349

[36] Sipos K., Sipos M., The developement and validation of the Hungarian form of the STAI, In: Spielberger, C.D. (Ed.), Cross-cultural anxiety, Hemisphere Publishing Corporation, Washington-London, US-UK, 1978

[37] IBM SPSS, Version 20, SPSS, Inc., Chicago, IL, USA, 2011

[38] Preacher K.J., Hayes A.F., Asymptotic and resampling strategies for assessing and comparing indirect effects in multiple mediator models, Behav. Res. Methods, 2008, 40, 879-891

[39] McRae K., Ochsner K.N., Mauss I.B., Gabrieli J.J.D., Gross J.J., Gender differences in emotion regulation: an fMRI study of cognitive reappraisal, Group Process. Intergroup Relat., 2008, 11, 143-162 
[40] Opitz P.C., Rauch L.C., Terry D.P., Urry H.L., Prefrontal mediation of age differences in cognitive reappraisal, Neurobiol. Aging, 2012, 33, 645655

[41] Yeung D.Y., Wong C.K.M., Lok D.P.P., Emotion regulation mediates age differences in emotions, Aging Ment. Health., 2011, 15, 414-418

[42] Zlomke K.R., Hahn K.S., Cognitive emotion regulation strategies: gender differences and associations to worry, Pers. Individ. Dif., 2010, $48,408-413$

[43] Schwabe L., Wolf O.T., Stress and multiple memory systems: from 'thinking' to 'doing', Trends Cogn. Sci., 2013, 17, 60-68

[44] Brewin C.R., Dalgleish T., Joseph S., A dual representation theory of post traumatic stress disorder, Psychol. Rev., 1996, 103, 670-686

[45] Cohen S., Janicki-Deverts D., Who's stressed? Distributions of psychological stress in the United States in probability samples from
1983, 2006, and 2009, J. Appl. Soc. Psychol., 2012, 42, 1320-1334

[46] Schroevers M., Kraaij V., Garnefski N., Goal disturbance, cognitive coping strategies, and psychological adjustment to different types of stressful life event, Pers. Individ. Dif., 2007, 43, 413-423

[47] Sowell E.R., Thompson P.M., Holmes C.J., Jernaqan T.L., Toga A.W., In vivo evidence for post-adolescent brain maturation in frontal and striatal regions, Nat. Neurosci., 1999, 2, 859-861

[48] Soares J.M., Sampaio A., Ferreira L.M., Santos N.C., Marques F., Palha J.A., et al. Stress-induced changes in human decision-making are reversible, Transl. Psychiatry, 2012, 2, 131

[49] Sakai Y., Kumano H., Nishikawa M., Sakano Y., Kaiya H., Imabayashi E., et al., Changes in cerebral glucose utilization in patients with panic disorder treated with cognitive-behavioral therapy, Neuroimage, $2006,33,218-226$ 